ORIGINAL PROF-2002

\title{
ACUTE AND CHRONIC IMMOBILIZATION STRESS;
}

Morphometric study of Purkinje cells of vermal cerebellar cortex of young male rats.

\author{
Dr. Bashir Ahmad Janjua
}

ABSTRACT...Objective: To compare the morphological changes induced by acute and chronic immobilization in vermal cerebellar cortex of young male sprague dawley rats with special reference to Purkinje cells. Study design: It was experimental. Setting: Department of Anatomy CPSP Reional Centre, Islamabad. Period: 2005 to 2007. Material and method: A total of 120 young male Sprague Dawley rats were taken and divided equally in two groups $(n=60$ in each). Both these groups were divided further into two subgroups ( $\mathrm{n}=30$ in each) control acute (CA), immobilized acute (IA), control chronic (CC) and immobilized chronic (IC). 'Immobilized acute' group IA was kept in restrainer for 24 hours continuously while 'immobilized chronic' group IC was kept in restrainer for 2 hours daily for fourteen days, one rat per restrainer separately. Sections stained with Hematoxylin and Eosin were studied under light microscope for observations and data was recorded. Results of experimental acute group were compared with those of experimental chronic'. SSPS version 10 was used for data analysis. Results: Changes in the shape and size of the soma and nucleus of the Purkinje cells were noted. The cells were looking like dried raisins in both experimental groups but these changes were more marked in acute experimental group as compared to controls. The size of the soma and nucleus of the Purkinje cells was reduced in both acute and chronic immobilized stressed groups' however; this reduction in the size of the soma and nucleus of the Purkinje cells was more pronounced in acute stressed group as compared to animals exposed to chronic stress. Total cell count and cell size was significantly decreased in both experimental groups as compared to their controls; however, it was more pronounced in acute stressed group as compared to animals exposed to chronic stress. Conclusions: Immobilization stress may act as a factor causing an imbalance in the metabolic activity of the neurons which can result in neuronal injury. The Purkinje neurons were affected more under the effect of acute stress as compared to chronic. The lesser effect in chronic stress is probably due to role of the phenomena of adaptation.

Key words: Acute, Chronic, Immobilization stress, Purkinje cells and vermal cerebellar cortex.

\section{Article Citation}

$\checkmark \quad$ Janjua BA. Morphometric study of Pukinje cells of vermal cerebellar cortex of young male rats under the effects of acute and chronic immobilization stress. Professional Med J Feb 2013;20(1):150-155.

\section{INTRODUCTION}

Hans Selye has worked a lot on stress and gave the proper scientific and medical concept in his book Stress of Life ${ }^{1}$. He was the first researcher, who used immobilization stress. Effects of different types of stressors like cold, hypoglycemia, and immobilization stress have been studied by other researchers ${ }^{2}$. Neuroendocrine role is necessary to cope with stress for survival in many stressful conditions ${ }^{3}$. On cessation of a specific stressor, the physiological systems are turned off efficiently ${ }^{4}$. Various studies on both acute and chronic immobilization stress induced changes on different organs such as, kidneys with tissue edema and cloudy swelling in epithelial cells of proximal and distal tubules ${ }^{5}$, adrenal gland showing vacuolar degeneration and brain cortex with formation of lesions $^{6}$ have been studied. Changes in the morphology and numerical density of cerebellar neurons of dams of immobilized pregnant rats for one hour have been observed ${ }^{7}$. The cerebellar Purkinje cells control muscular activities by influencing the muscle tone. People have studied the morphologic changes of neurons of aging in the form of accumulation of lipofuscin in their lysosomes ${ }^{8}$ or neuromelanin pigments ${ }^{9}$. From the results of various previous studies it has been noticed that oxidants are produced under the stress and cause damage to the cellular molecules such as, lipids and protein in the brain of the rat ${ }^{10}$. This damage to the cellular molecules leads death of the neurons. Significant age-related changes in rat cerebellar basket and granule cells have been studied for the mean volumes of the soma and ground substance ${ }^{11,12}$. 
Although, various parts of the rat cerebral cortex and lobes of rat cerebellum have been studied for immobilization induced changes and reported earlier but no reports are available on comparative study of effects of acute and chronic immobilization stress on morphometric study of Purkinje cells of vermal cerebellar cortex of young male rats.

The objective of the present study was to examine and compare the effects of acute and chronic immobilization stress on morphological changes of Purkinje cells of the vermal cerebellar cortex of young male sprague dawley rats.

\section{MATERIAL AND METHODS}

An experimental study was designed and carried out at Anatomy Department of CPSP Regional Center Islamabad. Total 120 healthy young male Sprague Dawley rats of 12 weeks age were purchased from National Institute of Health Islamabad, kept at CPSP Regional Centre Islamabad, housed singly in their home cages for adaptation to the new environment for a week under controlled conditions and fed on the standard diet and tap water ad libitum. For experimental procedure, locally made immobilization device was used as a restrainer. For study purpose, animals were equally divided into two groups i.e. for acute (Group A) and chronic (Group B) immobilization stress. Group A: Total 60 animals, divided in two subgroups. Control acute subgroup $(C A)=30$ animals. Immobilized acute subgroup $(I A)=30$ animals. Group B: Total 60 animals, divided in two subgroups. Control chronic subgroup (CC) $=30$ animals. Immobilized chronic subgroup $(\mathrm{IC})=30$ animals.

Animals of control acute (CA) and immobilized acute (IA) subgroups were removed from their home cages and weighed on the day of experiment before stress. Animals of control (CA) subgroup were placed into their labeled cages, one animal per cage, for the period of 24 hours in continuation, free to move in their cages, but the animals of immobilized acute (IA) subgroup were immobilized, separately by placing them into their labeled restrainers, one animal per restrainer and were not free to move in their cages. The period of immobilization was for 24 hours continuously. Animals of both subgroups (CA) and (IA) subgroups were supplied only water but their food was restricted during experiment. After the completion of experimental procedure, animals of subgroups (CA) and $(I A)$ were removed from their cages and restrainers respectively, and all the rats of both subgroups were anaesthetized and operated on the same day, one by one on their turn, to remove the whole brain with cerebellum. 10\% formalin was used as a fixative for the storage of brain tissue. For chronic immobilization stress (CIS), the animals of control (CC) and immobilized(IC) subgroups were removed from their home cages and placed into their separate labeled cages, one animal per cage, for the period of 14 days, free to move in their cages in case of (CC) subgroup, but the animals of immobilized (IC) subgroup, placed into their labeled restrainers, one animal per restrainer were not free to move inside their restrainer for 14 days. Food was restricted to all the animals except during the period of experiment. Soon after the completion of the experimental protocol for fourteen days, the whole brain with cerebellum of all the rats was removed, stored in $10 \%$ formalin.

The vermis was cut into two equal halves through a midsagittal incision. One piece processed to get the sections in transverse plane to cut sections for counting Purkinje cells located along the border of the folium of the cerebellum. Five $\mu \mathrm{m}$ thick sections were cut, stained with Hematoxylin and Eosin for examination under light microscope. To find P-value, SPSS version 10 was applied.

\section{RESULTS}

Significant decrease in cell size was noticed, while insignificant decrease in nuclear size and nuclear cytoplasmic ratio was found in stressed rats of both acute and chronic groups. Difference between the cell 
size in experimental acute $(17.62 \pm 0.30 \mu \mathrm{m})$ and control acute $(18.58 \pm 0.24 \mu \mathrm{m})$ subgroups showed significantly $(p<0.05)$ * more decreased as compared with the difference between the experimental chronic $(17.82 \pm 0.20 \mu \mathrm{m})$ and control chronic $(18.43 \pm 0.19 \mu \mathrm{m})$ subgroups. Difference between the nuclear size in experimental acute $(9.77$ $\pm 0.23 \mu \mathrm{m})$ and control acute (10.32 $\pm 0.15 \mu \mathrm{m})$ subgroup was found more than the difference between the experimental chronic $(10.21 \pm 0.13 \mu \mathrm{m})$ and control chronic $(10.49 \pm 0.12 \mu \mathrm{m})$ subgroups, although it was insignificant. Similarly difference between the nuclear cytoplasmic ratio in experimental acute $(0.55 \pm 8.65)$ and control acute $(0.56 \pm 1.25)$ subgroup was found more than the difference between the experimental chronic $(0.57 \pm 8.61)$ and control chronic $(0.56 \pm 7.21)$ subgroups, although it was insignificant. No significant $(p>0.05)$ differences were observed in cell size, nuclear size and nuclear cytoplasmic ratio on comparing the means of the experimental acute and experimental chronic subgroups. However, decrease in cell size, nuclear size and nuclear cytoplasmic ratio was more pronounced in experimental acute subgroup than in experimental chronic subgroup (Table-I).

Significant decrease in total cell count / $\mathrm{mm}$ was found in stressed rats of both experimental i.e., $\mathrm{Al}$ and $\mathrm{Cl}$ subgroups as compared with their controls. Total cell count / mm was statistically highly significantly $(p=$ $0.001) * * *$ less $(21.19 \pm 0.36)$ in experimental acute subgroup than $(23.45 \pm 0.49)$ in control acute subgroup while total cell count / $\mathrm{mm}$ was significantly $(p<0.05)$ * less $(22.52 \pm 0.29)$ in experimental chronic subgroup than $(23.61 \pm 0.39)$ in control chronic subgroup. Significant $(p<0.05)$ * difference was observed in total cell count / $\mathrm{mm}$ on comparing the means of the experimental acute and experimental chronic subgroups. However, decrease in total cell count / $\mathrm{mm}$ was more pronounced in experimental acute subgroup than in experimental chronic subgroup (Table-II).

\begin{tabular}{|l|c|c|c|}
\hline Parameters & $\begin{array}{c}\text { Exp. Acute } \\
\text { (Subgroup } \\
\text { lb) Mean } \pm \\
\text { SE }(\mathbf{n}=\mathbf{3 0})\end{array}$ & $\begin{array}{c}\text { Exp. Chronic } \\
\text { (Subgroup } \\
\text { Ilb) Mean } \pm \\
\text { SE }(\mathbf{n}=\mathbf{3 0})\end{array}$ & $\begin{array}{c}\text { P-value of } \\
\text { difference }\end{array}$ \\
\hline Cell size $(\mu \mathrm{m})$ & $\begin{array}{c}17.62 \pm \\
0.30\end{array}$ & $\begin{array}{c}17.82 \pm \\
0.20\end{array}$ & $\mathrm{P}>0.05$ \\
\hline $\begin{array}{l}\text { Nuclear size } \\
(\mu \mathrm{m})\end{array}$ & $\begin{array}{c}9.77 \pm \\
0.23\end{array}$ & $\begin{array}{c}10.21 \pm \\
0.13\end{array}$ & $\mathrm{P}>0.05$ \\
\hline $\begin{array}{l}\text { Nuclear } \\
\text { cytoplasmic } \\
\text { ratio }\end{array}$ & $\begin{array}{c}0.55 \pm \\
8.65\end{array}$ & $\begin{array}{c}0.57 \pm \\
8.61\end{array}$ & $\mathrm{P}>0.05$ \\
\hline
\end{tabular}

Table-I. Cell size, nuclear size and nuclear cytoplasmic ratio in acute and chronic immobilization stress

\begin{tabular}{|l|c|c|c|}
\hline Parameters & $\begin{array}{c}\text { Exp. Acute } \\
\text { (Subgroup } \\
\text { Ib) Mean } \pm \\
\text { SE }(\mathbf{n}=\mathbf{3 0})\end{array}$ & $\begin{array}{c}\text { Exp. Chronic } \\
\text { (Subgroup } \\
\text { Ilb) Mean } \pm \\
\text { SE }(\mathbf{n = 3 0})\end{array}$ & $\begin{array}{c}\text { P-value of } \\
\text { difference }\end{array}$ \\
\hline $\begin{array}{l}\text { Cell count / } \\
\mathrm{mm}\end{array}$ & $\begin{array}{c}21.19 \pm \\
0.36\end{array}$ & $\begin{array}{c}22.52 \pm \\
0.29\end{array}$ & $\mathrm{P}<0.05$ \\
\hline \multicolumn{2}{|c|}{ Table-II. Purkinji cell count in acute and chronic } \\
immobilization stress
\end{tabular}

\section{DISCUSSION}

This project had an objective to observe and compare the morphological changes in morphological changes of Purkinje cells of vermal cerebellar cortex of young male Sprague Dawley rats, when exposed to acute and chronic immobilization stress.

\section{CELL COUNT}

Total cell count / $\mathrm{mm}$ was significantly reduced $(p<0.05)^{*}$ in chronic experimental subgroup but reduction in acute immobilization was highly significant $(p=0.001) \star * \star$ which showed more pronounced effect in acute than in chronic immobilization stress. The decrease in cell count in this study could be due to the production of reactive oxygen species, produced during the process of immobilization stress (IS), which is in agreement with a previous study ${ }^{13}$ where increase in the levels of reactive oxygen species (ROS) in the cerebral cortex 
after exposure to immobilization stress (IS) was seen. In our study, significant decrease in cell count in chronically stressed rats was also in accordance with a previous study in which Jytte et al found $11 \%$ decrease in Purkinje cell count in sedentary aged rats $^{14}$. It appears that immobilization may impair brain functions and increase vulnerability to cell injury leading to neuronal death in the rat cerebellar cortex and as a result, cell count is decreased. Larsen et al ${ }^{15}$ found less number of Purkinje cells in sedentary aged rats as compared to exercised aged rats which is similar to the results found in chronically immobilized stressed rats as compared to controls in our study. They also found the same number of Purkinje cells in exercised aged rats as in young rats which is again in agreement with the results of this current study.

Lipid peroxidation causes cellular damage and may explain why AIS causes neuronal loss in the brain. In the present study, neuronal loss is in accordance with a previous study ${ }^{16}$ in which, malondialdehyde (MDA) level was significantly increased in the cerebral cortex after immobilization stress, which caused oxidative damage to lipids, proteins, and DNA in the brain of rats. The decrease in cell count in the present study also signifies the vulnerability of Purkinje's cells, which may be related to metabolic or oxidative changes, occurring in the brain cells of animals, on exposure to acute or chronic IS or in old age, however the effect was found more pronounced in acute stress as compared to chronic stress.

\section{CELL SIZE, NUCLEAR SIZE, AND NUCLEAR CYTOPLASIMIC RATIO}

Significant decrease in cell size was observed in both acute and chronic experimental subgroups as compared with their control subgroups in this study. An insignificant decrease in nuclear size and nuclear cytoplasmic ratio was seen in both acute and chronic experimental subgroups as compared with their controls. The above said changes were more pronounced in AIS as compared with CIS. The morphological changes are in agreement with a previous study in which Rodrigo et al observed severely impaired Purkinje cell dendritic growth in male and female Sprague-Dawley albino rats when their movements were restricted during the early post weaning period ${ }^{17}$. The results of our study are also in accordance with the results of a study, done by Jytte et al where they found immobilization induced decrease in Purkinje cell count, and decreased volumes by $9 \%$ than in exercised aged rats. The exercised aged rats had the same number of Purkinje cells as young rats ${ }^{18}$. So our life style and health habits can damage the neurons and this nerve cell injury may be prevented or delayed by physical exercise.

Rodrigo et $\mathrm{al}^{19}$ also explained in their studies about the adulthood. Improved level of glucocorticoid receptors (GR) and nuclear transporter protein 70 (Hsp70) have been observed in previous studies on the neurons of hippocampus and brain cortex of adult male Wistar rats exposed to acute immobilization and chronic social isolation stress after repeated exercise but the improvement in detrimental effects of chronic stress was better as compared to acute stress which is in agreement with the results of our study ${ }^{20}$.

\section{CONCLUSIONS}

Immobilization stress may act as a factor causing an imbalance in the metabolic activity of the neurons which can result in neuronal injury. The Purkinje neurons were affected more under the effect of acute stress as compared to chronic. The lesser effect in chronic stress is probably due to role of the phenomena of adaptation.

\section{Copyright@ 25 0ct, 2012.}

\section{REFERENCES}

1. Selye H. Stress without distress. New York: New York American Library 1974.

2. Pacak K, Palkovits M, Yadid G, Kvetnansky R, Kopin IJ, Goldstein DS et al. Heterogeneous neurochemical responses to different stressors: a test of Selye's 
doctrine of nonspecificity. Am J Physiol 1998; 275:R1247-R1255.

3. Cohen F, Lazarus $\mathrm{R}$ Coping with the stresses of illness. In: Stone GC, Cohen F, Adler NE, eds. Health physiology: a handbook. San Francisco: Jossey-Bass; 1979; 217-254.

4. McEwen BS. Stress, brain, and behavior: life-long effects upon health and disease. In: Kinney JM, Tucker $\mathrm{HN}$, eds. Physiology, stress, and malnutrition. Functional correlates of nutritional intervention. Philadelphia: Lippincott-Raven; 1997;113-130.

5. Vesna S, Nada V, Nenad B, Aleksandra D. Histopathologic changes in rat kidneys exposed to acute and chronic immobilization stress. Stress and Health. 2011;27(3):195-198.

6. Kulkarni MP, Juvekar AR. Attenuation of Acute and Chronic Restraint Stress-induced Perturbations in Experimental Animals by Nelumbo nucifera Gaertn. Indian J Pharm Sci. 2008 May-Jun; 70(3): 327-332.

7. Emel U, Ferruh Y, Gursel 0. The effects of prenatal stress on the Purkinje cell neurogenesis Neurotoxicology and Teratology. 2006;28 (1): 86-94.

8. My paper] Eduardo AP. Pigments in aging: an overview. Ann N Y Acad Sci. 2002 Apr ;959:57-65.

9. David S, Eugene M, Zsolt T, Fabio AZ, John DS, Luigi Z. Neuronal pigmented autophagic vacuoles: lipofuscin, neuromelanin, and ceroid as macroautophagic responses during aging and disease. J Neurochem 2008;106(1):24-36.

10. Jiankang L, Xiaoyan W, Mark K, Shigenaga, Helen C, Yeo AM et al. Immobilization stress causes oxidative damage to lipid, protein, and DNA in the brain of rats. FASEBJ 1996; 10:1532-8.

11. Rui MF, Henrique, Eduardo R, Alcinda R, Ricardo M, Maria $\mathrm{H}$. Oliveira, et al. Age-related changes in rat cerebellar basket cells: a quantitative study using unbiased stereological methods. J Anat. 2001 June; 198(Pt6): 727-736.
12. Henrique RM, Monteiro RA, Rocha E, Marini-Abreu MM. A stereological study on the nuclear volume of cerebellar granule cells in aging rats. Neurobiol Aging. 1997 Mar-Apr;18(2):199-203.

13. Lee YJ, Choi B, Lee EH, Choi KS, Sohn S Immobilization stress induces cell death through production of reactive oxygen species in the mouse cerebral cortex. Neurosci Lett 2006; 392:27-31.

14. Jytte 0 L, Monika Skalicky, Andrus V. Doe's long-term physical exercise counteracts age-related Purkinje cell loss? A stereological study of rat cerebellum. J Comp Neurol 2000; 428:213-22.

15. Larsen J0, Skalicky M, Viidik A. Does long-term physical exercise counteract age-related Purkinje cell loss? A stereological study of rat cerebellum. J Comp Neurol. 2000 Dec 11;428(2):213-22.

16. Jiankang L, Xiaoyan W, Mark K, Shigenaga, Helen C, Yeo AM et al. Immobilization stress causes oxidative damage to lipid, protein, and DNA in the brain of rats. FASEBJ 1996; 10:1532-8.

17. Rodrigo P María C, Hervias M E, Tohá AV, Héctor RF. Purkinje Cell Impairment Induced by Early Movement Restriction. Biology of the Neonate 1998; 73:47-51.

18. Jytte OL, Monika S, Andrus V. Doe's long-term physical exercise counteracts age-related Purkinje cell loss? A stereological study of rat cerebellum. J Comp Neurol 2000; 428:213-22.

19. Rodrigo P, Daniela E, Rodrigo A, María JU. Carlos Bustamante .Maternal stress induces long-lasting Purkinje cell developmental impairments in mouse offspring. Eur J Pediatr. 2010 Dec ;169 (12):1517-22 20652312

20. Dragana F, ljubica G, Sladjana D, Marija B. Radojčić The Effect of Repeated Physical Exercise on Hippocampus and Brain Cortex in Stressed Rats. Volume 1096, Signal Transduction Pathways, Part D: Inflammatory Signaling Pathways and Neuropathology, January 2007; 207-219. 
AUTHOR(S):

1. DR. BASHIR AHMAD JUNJUA MBBS, FCPS

Associate Professor Anatomy

Department Sheikh Zayed Medical College

Rahim Yar Khan
CORRESPONDENCE ADDRESS:

Dr. Fauzia Zafar

Associate Professor

Pediatric Medicine Unit-I Nishtar Medical College

\& Hospital, Multan.

fauziawaqar@yahoo.com
Article received on: 08/05/2012 Accepted for Publication: $\quad$ 25/10/2012 Received after proof reading: 10/12/2012

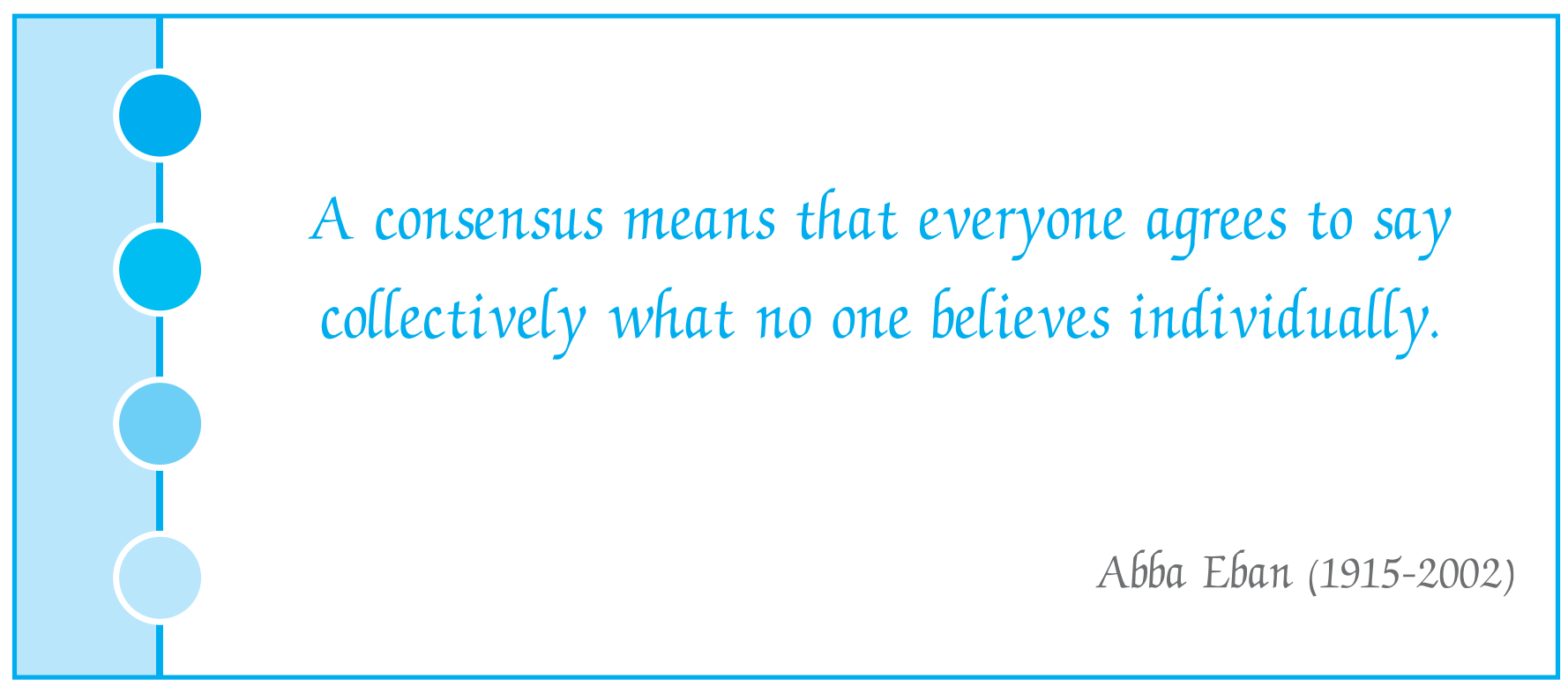

